\title{
The role of renewables in the energy crisis
}

GianVincenzo Fracastoro

Energy Department, Politecnico di Torino, Corso Duca degli Abruzzi 24, 10131 Torino (Italy)

\begin{abstract}
The recent progress of human kind has so far been strongly related to the use of fossil fuels. Nowadays, the uncontrolled growth of their use is producing a series of threats such as local pollution, global warming, and the unbalance between their growing demand and their progressive depletion is creating serious geopolitical frictions which may put at risk our civilization. While the nuclear option is seriously questioned in the Western world, the growth of renewable energy sources (RES) is creating the illusion that they may just replace fossil fuels and become a sort of panacea overcoming all aforementioned threats. Some of the shortcomings of this way of thinking are underlined in this paper. Actually, the correct answer is a combination of two factors: on one side the use of renewable energy sources, but on the other side the adoption of energy efficiency measures in order to rationalize the energy demand.
\end{abstract}

\section{The "perfect storm"}

\subsection{Greenhouse Gases and energy}

Thousands of papers have been probably written about the consequences of the increasing amount of $\mathrm{CO}_{2}$ and other Green House Gases (GHG) on the Earth temperature. The last report from the Intergovernmental Panel for Climate Change (IPCC), the most authoritative group of climate experts recently issued in 2013, does not leave many doubts about this: if the increasing $\mathrm{CO}_{2}$ concentration trend will remain the same of today in the few next decades, temperature increase at the end of the century may reach $3-5^{\circ} \mathrm{C}$, with dramatic consequences.

While the entity of these effects is sometimes debated, it is well known where GHG emissions come from. Almost 2/3 of them are due to energy conversion of fossil fuels (coal, oil or natural gas), namely industry (14\%), power plants (24\%), transport (14\%), buildings (8\%) and other energy related issues, as can be seen in Figure 1.

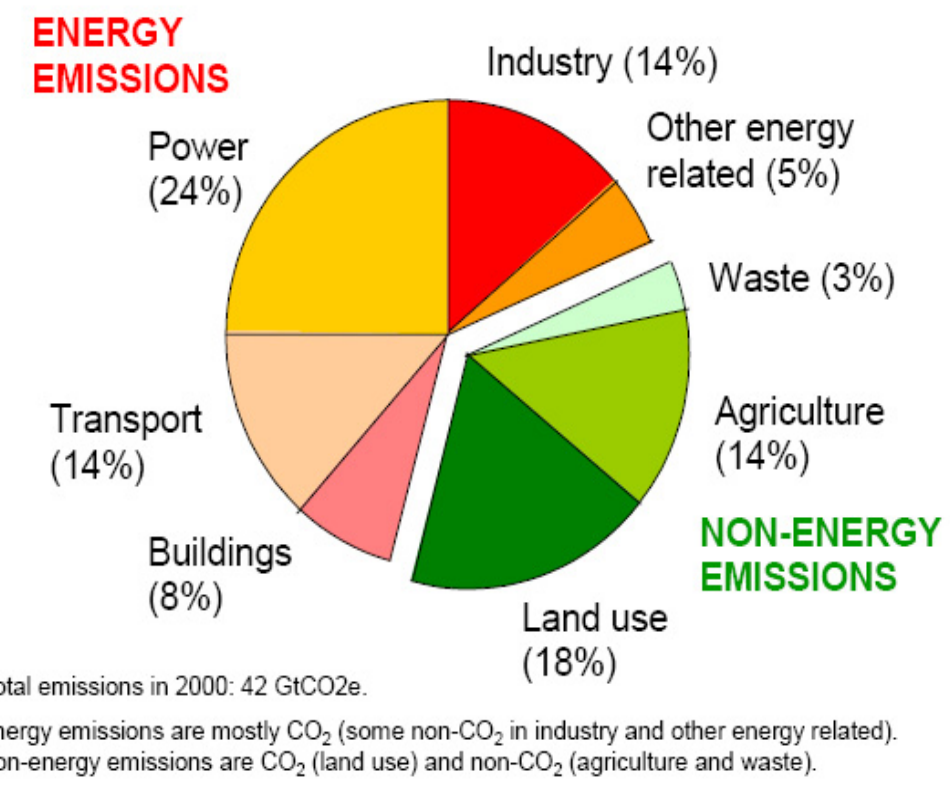

Figure 1 - World GHG emissions and its sources [1].

This is an Open Access article distributed under the terms of the Creative Commons Attribution License 2.0, which permits unrestricted use, distribution, and reproduction in any medium, provided the original work is properly cited. 


\subsection{Local pollution}

Beyond global effects on world climate, fossil energy conversion processes in buildings, factories, transportation are responsible for local pollution, especially in urban and densely populated areas, leading to the release of million tons per year of particulate matter, sulfur oxides, carbon monoxide and nitrous oxides (as shown in figure 2) in the air we breath. Health consequences are nowadays fully acknowledged by medical science.

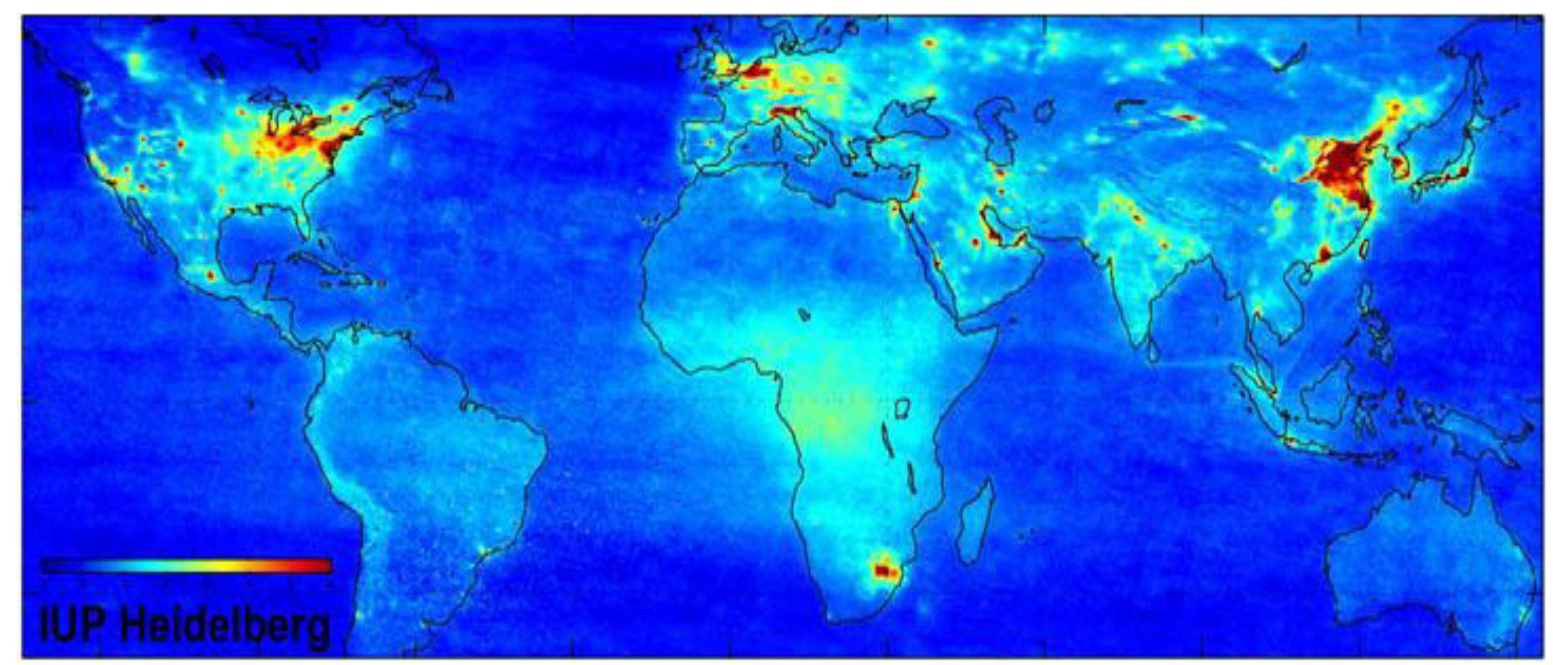

Figure $2-\mathrm{NO}_{2}$ concentrations around the world [2].

\subsection{Unbalanced energy consumption}

World per capita primary energy consumption (toe/person) differs by an order of magnitude between rich OECD countries like USA, Canada or Norway and most of African, Asian, or South American countries (see figure 3). This unbalance is in the long run going to be reduced.

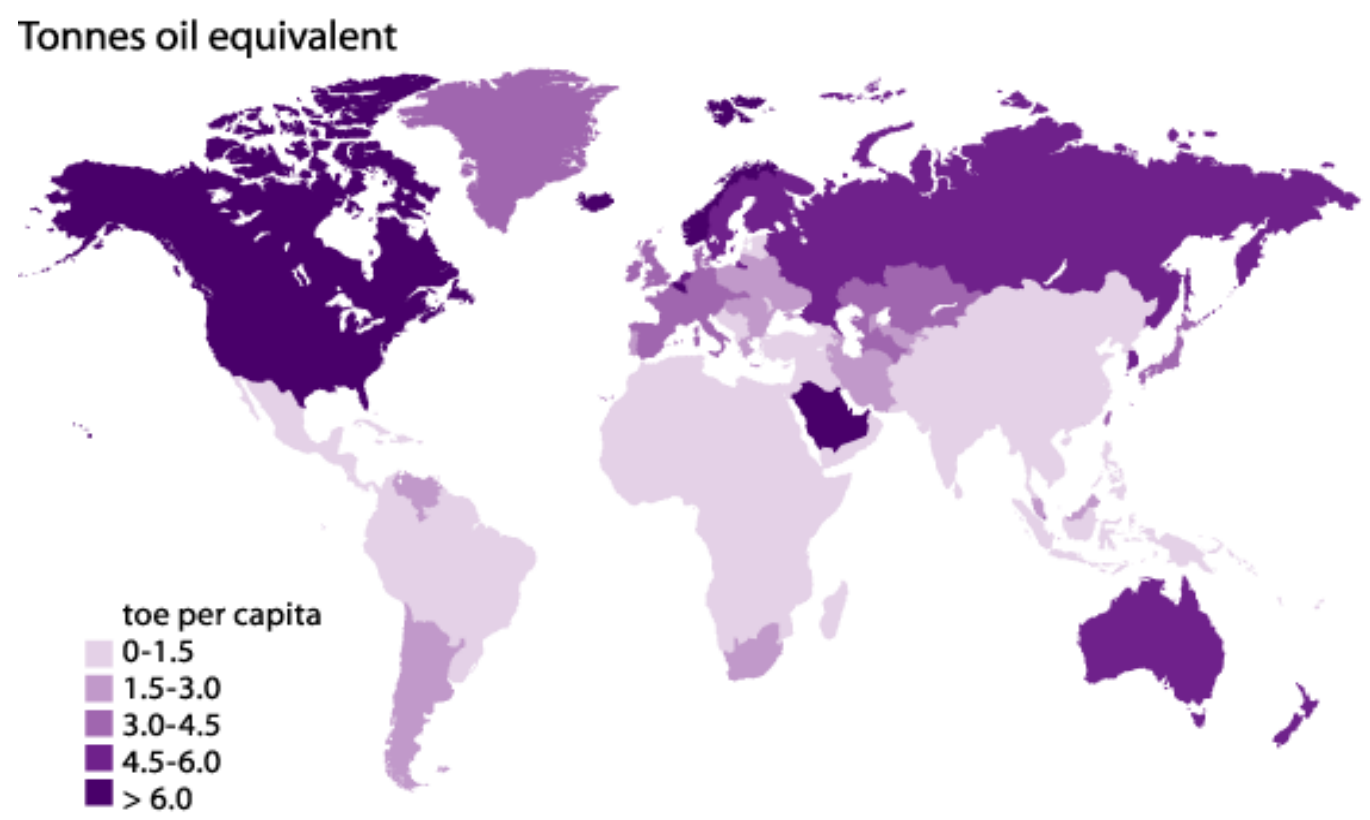

Figure 3 - World per capita energy consumption [3].

Emerging economies (China, India, Indonesia, Brazil,...) are rapidly catching up, in a search for better quality of life for their populations. As a result, if we observe energy consumption trends in the different World regions, we will notice strong differences: from the constant and even declining slope of our old Europe to the slightly increasing trend of North America to the high-rocketing tendency of Asia Pacific (see figure 4). If China alone should reach the same per capita energy consumption of Italy it would more than double the Asia Pacific share, pushing world consumption to a thrilling 17,000 Mtoe. As a consequence, $\mathrm{CO}_{2}$ emissions would increase even more so, due to the high share of poor quality coal in China's power mix. 


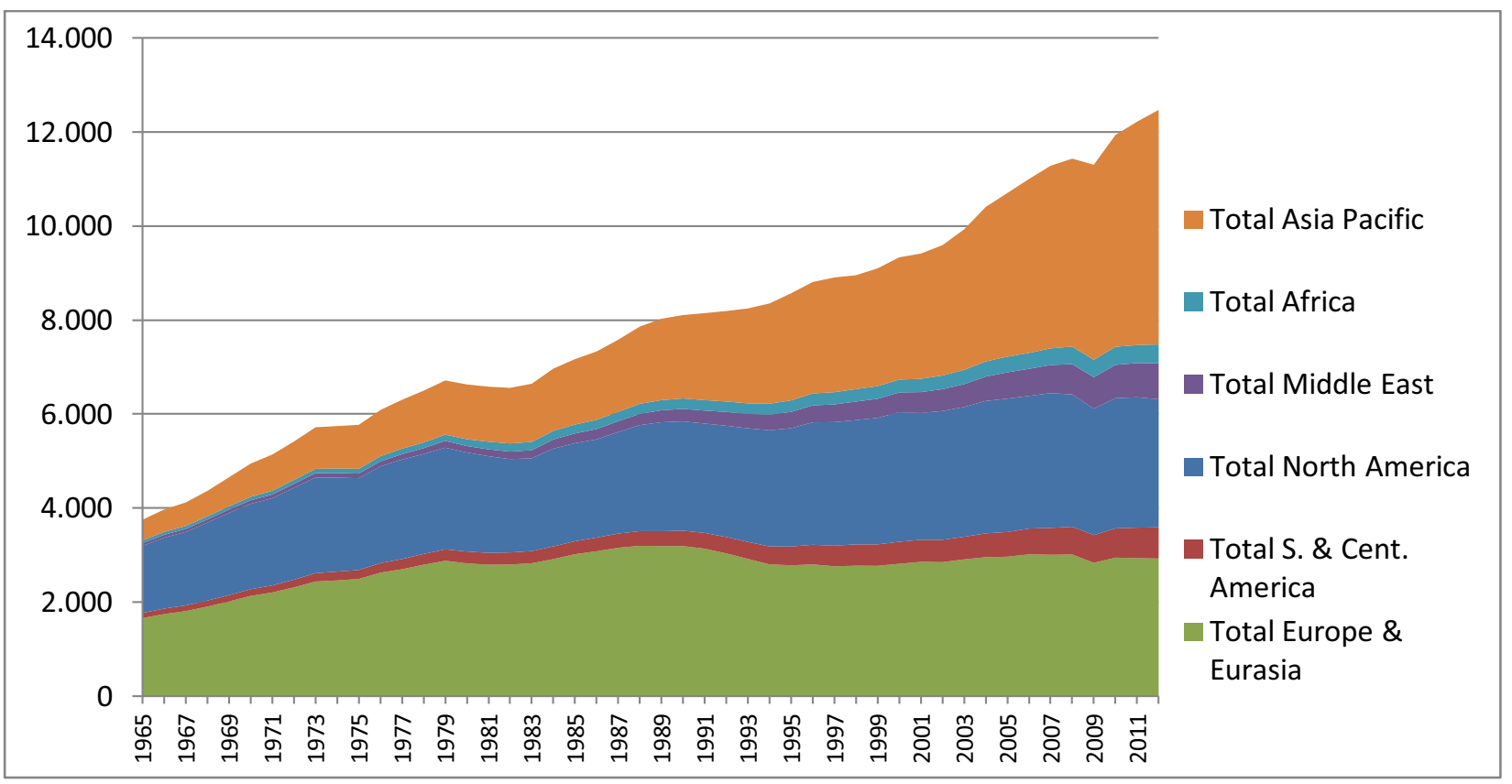

Figure 4 - World Energy consumption per Region [3].

\subsection{Price of fossil fuels}

Finally, looking at oil prices from 1861 onwards, we may see that prices above 100 \$barrel (in 2012 \$) have already been reached in the past (Figure 5), but are now steadily exceeded, and the price is not likely to decrease in the future, with growing demand and progressively reducing "low hanging fruits", or low-cost exploitable gas and oil reserves.

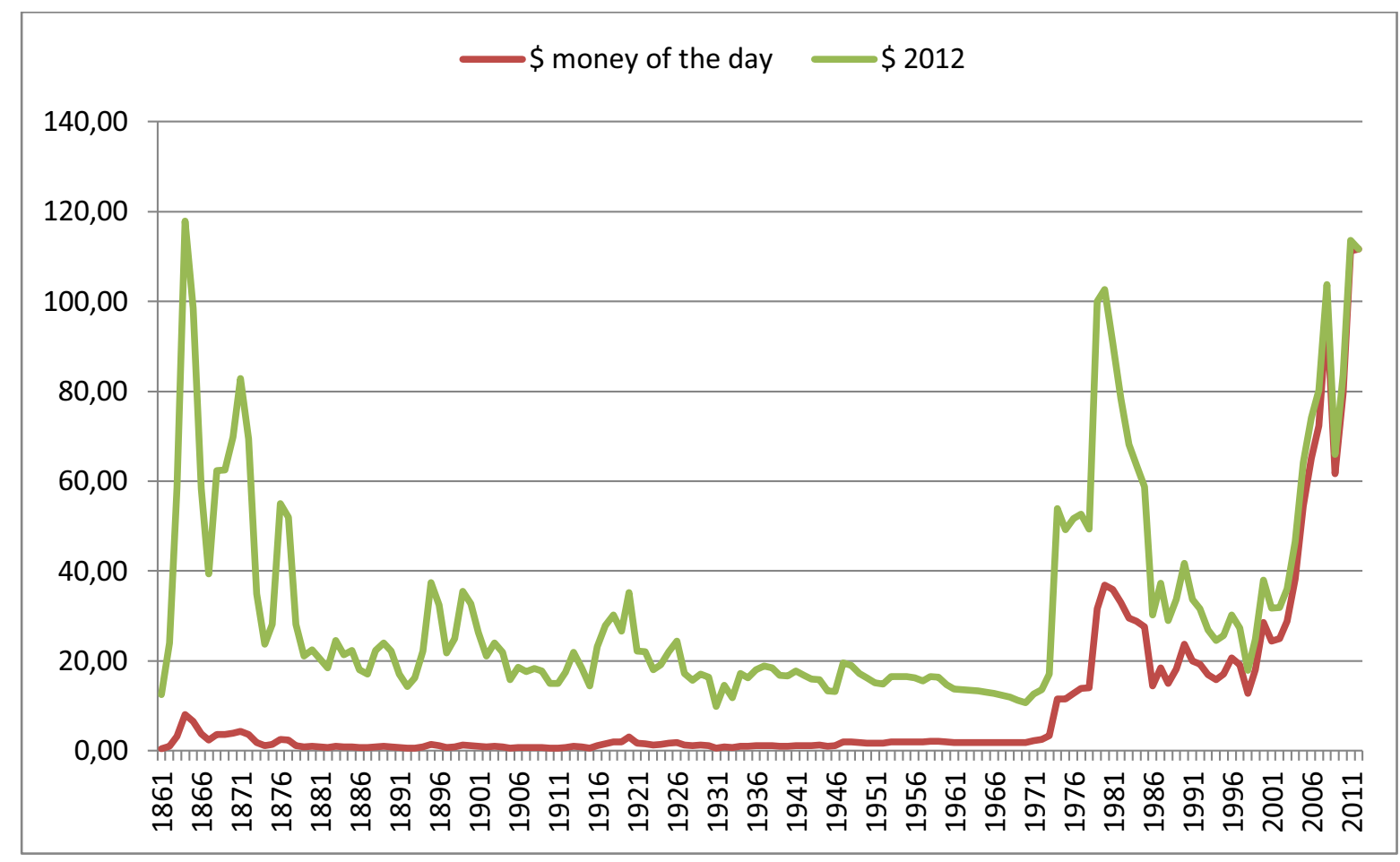

Figure 5 - Oil cost in \$ of the year and present day \$ (2012) [3].

All these factors (global environmental aspects, pollution problems in high population density and urban areas, expected rapid increase of energy demand by emerging economies, progressive depletion and increasing cost of fossil energy sources) add up creating a threatening scenario that has been dubbed "the perfect storm" by Bob Armstrong, vice President of MIT-Energy Initiative.

Furthermore, ominous "monsters" [4] are behind the door: 
- a 1-3-meter rise in sea level by the end of this century

- major alterations of the global hydrological cycle

- major changes in forest cover

- major emissions of greenhouse gases from the tundra.

All these phenomena may have strong feedbacks in a world "out of control", and "today's science cannot predict how much atmospheric change would let these monsters in, nor how quickly they could enter" [5].

\section{Will Renewable Energy Sources be the solution?}

Apart from the climate change sceptical people (more numerous than expected within the political class and among technicians and economists), those who take seriously these threats may be divided in two categories: those who think that the problem cannot be easily solved and those who think that the solution is already at hand. These last (a decreasing cohort of nuclear fission fans or fusion-devotees, and an increasing army of Renewable Energy Sources followers) think that just replacing fossil fuels with carbon-free ones will solve any problem, and make monsters and storms suddenly vanish. Actually, this is not the correct solution, and maybe not even a feasible one.

\subsection{Advantages of RES}

Advantages of RES are well known: they are perennial and free (except biomass), non-polluting during conversion process (except biomass), and fairly distributed in practically every country: there are areas rich with running rivers or mountain water basins, sunny areas, regions which are swept by strong and regular winds, or covered by thick forests or with coastal areas washed by waves, or tides, or ocean streams... Renewable energy is really everywhere!

Devices for RES exploitation are becoming cheaper and cheaper. Moreover, the different structure of the cost of RES with respect to fossil fuels should be stressed: while energy produced from fossil fuels is mainly paid for the extraction and depletion of matter which would take million years to be recreated, cost of energy produced by RES actually derives from labour costs required to fabricate the energy conversion devices (solar collectors, photovoltaic panels, wind turbines, etc.). Since most of the materials required to build these devices can be recycled (most PV installers guarantee for free final decommissioning and recycling of installations), what we are actually paying for is good jobs in high-tech sectors.

\subsection{Disadvantages of RES}

However, RES also have a number of shortcomings.

- They are diluted, with energy densities ranging between a few $\mathrm{W} / \mathrm{m}^{2}$ to less than $1 \mathrm{~kW} / \mathrm{m}^{2}$, compared to the $\mathrm{MW} / \mathrm{m}^{2}$ scale of fossil fuel power plants. This inherently leads to large and costly installations and to extensive land use.

- They are discontinuous and not exploitable at will or readily storable (except biomass, hydro and geothermal power). Discontinuous often goes along with unpredictable or at least partially predictable, except with short notice, and always with arbitrary. These two drawbacks reduce "de facto" the value of the energy produced by RES, and inherently create the need for costly back-up, or storage systems which are rather inefficient, expensive and often make use of environmentally unfriendly materials (just think of lead and cadmium of electric batteries).

- Another issue concerns the Life-Cycle balance of energy production from RES. While it's certainly true that energy is produced without any primary energy use by RES, on a Life-Cycle approach this is no longer true, as all RES conversion devices require energy for their construction. Usually, the energy required by construction of RES conversion devices is orders of magnitude smaller than the energy produced during their lifetime. To make an example, energy produced by a wind turbine during its lifetime is 50-60 times larger than the energy required for its construction. On the contrary, the high energy intensity of PV production makes this analysis more uncertain.

- The same should apply when a $\mathrm{CO}_{2}$ life cycle analysis is carried on. Avoided $\mathrm{CO}_{2}$ emissions should outpace $\mathrm{CO}_{2}$ emissions during RES conversion devices fabrication. This analysis partially goes along with that on primary energy use LCA, with some differences which should not be neglected.

\section{$2.3 \mathrm{CO}_{2}$ emissions by PV panels}

This paragraph will analyse the issue of PV life cycle $\mathrm{CO}_{2}$ emissions. The $\mathrm{CO}_{2}$ avoided will depend on the energy produced and the $\mathrm{CO}_{2}$ emitted on the energy required by construction. Energy and $\mathrm{CO}_{2}$ consumption/emission and production/avoided emission will respectively depend on where and how is the PV panel produced, and where and how is the PV panel installed. A PV panel produced in China (mostly with low quality coal-made electricity) and installed in Switzerland (with $1200 \mathrm{kWh} / \mathrm{m}^{2}$ solar irradiation) will hardly have a positive $\mathrm{CO}_{2}$ balance in its lifetime (see fig. 6), 
while a PV panel fabricated in Europe and installed in Sicily (almost $2000 \mathrm{kWh} / \mathrm{m}^{2}$ solar irradiation) will start having a positive $\mathrm{CO}_{2}$ emissions balance after less than 7 years.

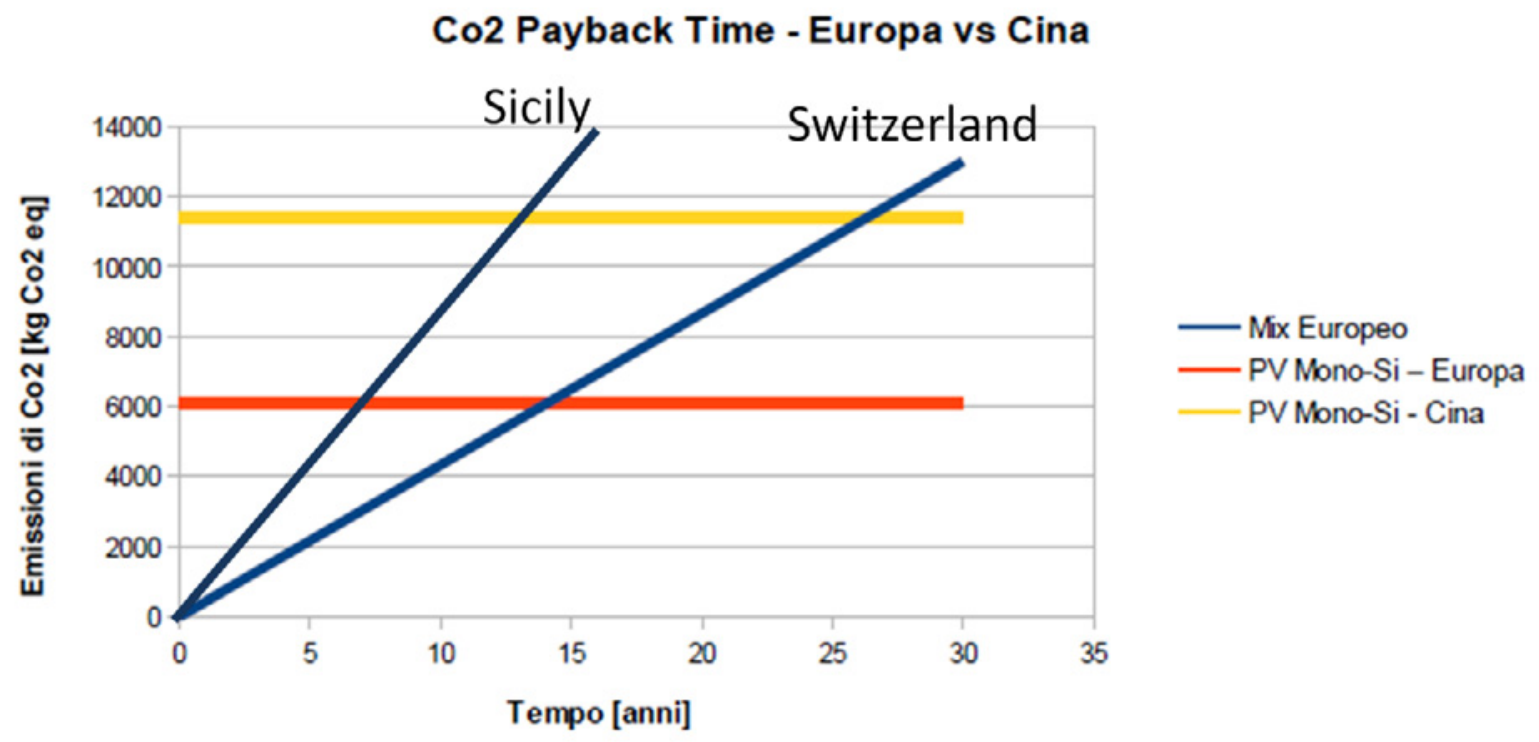

Figure 6 $-\mathrm{CO}_{2}$ emissions during PV fabrication and avoided emissions during their lifetime [6].

\subsection{Limitations imposed to RES by the grid}

Another even more limiting important factor is related to the grid, and to the mix of power production installations available in the country where renewable energy is produced. If it's not possible to count on the possibility to export or store excess power, solar power should not exceed a certain fraction of total installed capacity, otherwise it will results in a waste of energy. As an example, in Spain, a power mix with: 55\% Base load (with 30\% elasticity), 20\% Wind, 15\% Solar and 10-15\% Gas Turbines will result in the month of August in a non-negligible waste of energy, emphasized in Figure 7 by yellow peaks going beyond the red curve representing the energy demand [7].

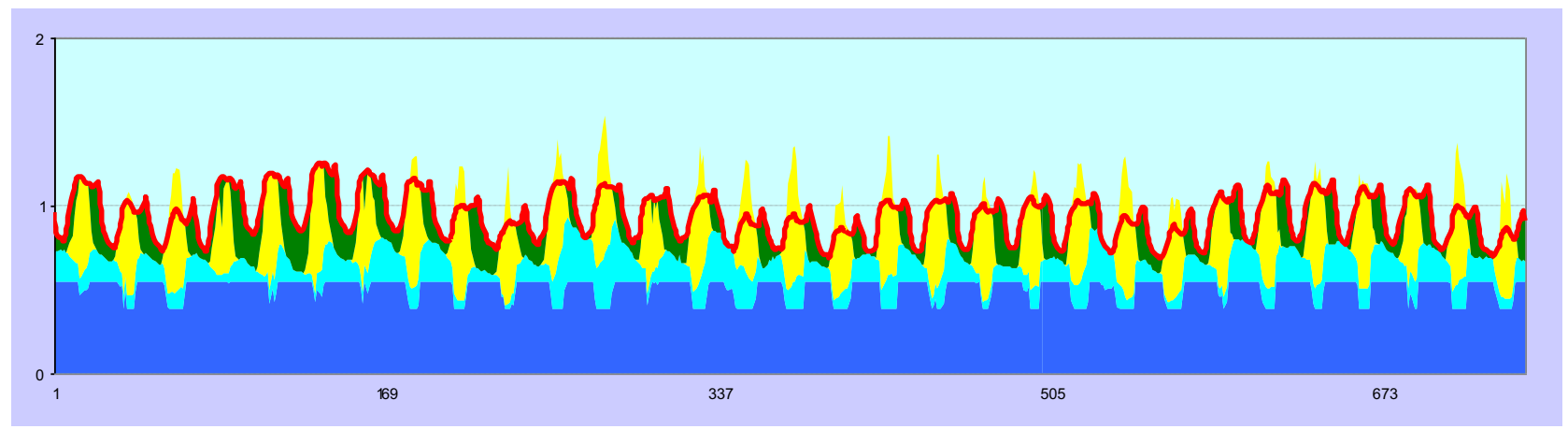

\section{Base load with an elasticity factor \\ Wind power \\ Solar power \\ Power generated with gas turbines \\ Demand

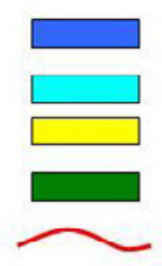

Figure 7 - Power production and demand profiles in August on the Spanish Grid with 20\% wind and 15\% PV [7].

A generalization of these results is shown in Figure 8 with a $50 \%$ base load and $20 \%$ wind share. For example, with $20 \%$ base load elasticity a $10 \%$ PV share will generate an energy excess (waste) below $0.5 \%$, while with $20 \%$ PV the waste energy will grow by a factor of 10 above $5 \%$. 


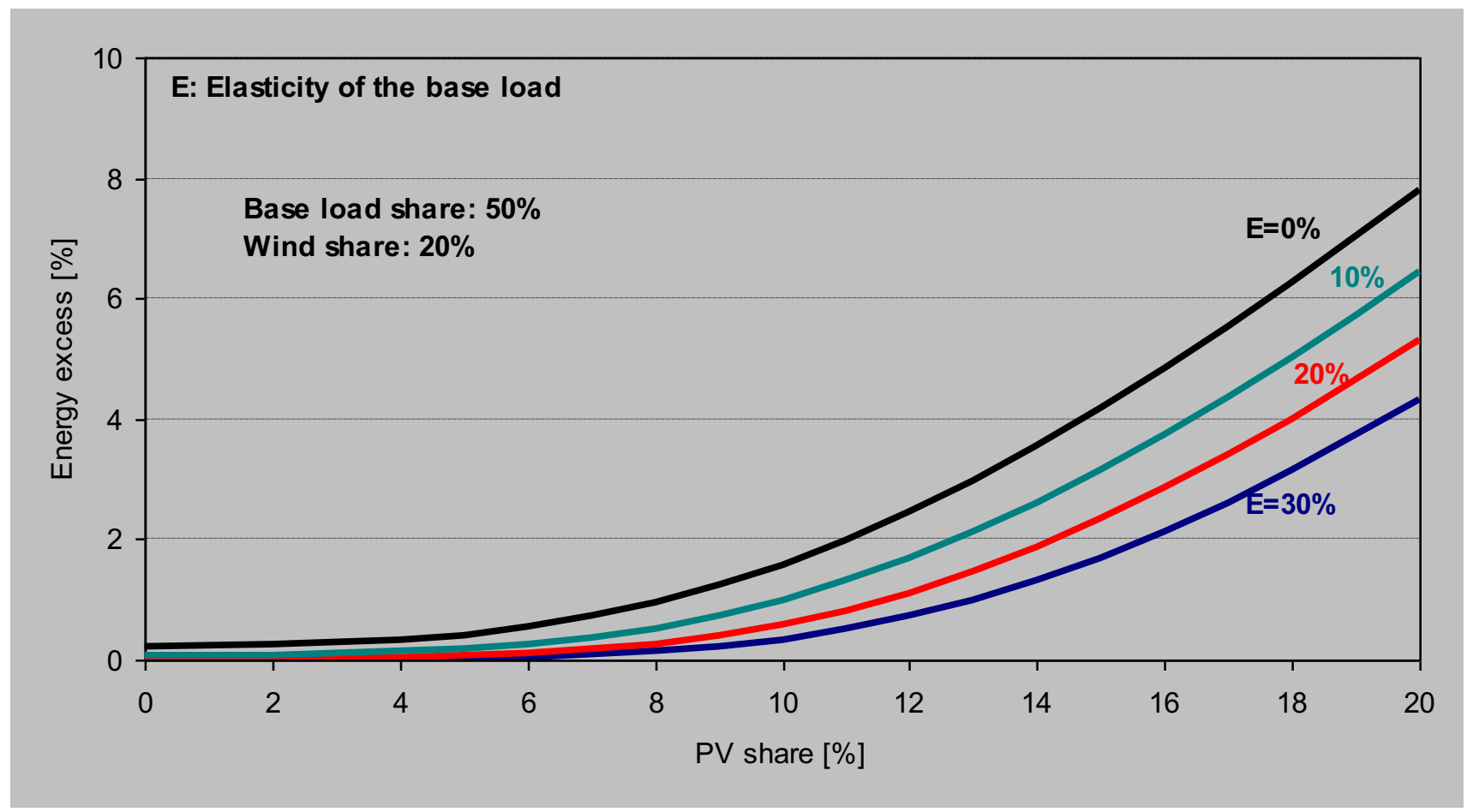

Figure 8 - Energy excess for different combinations of base load elasticity and PV share for Spain [7].

\section{Demand side management}

The drawbacks previously shown clarify the fact that simple replacement of fossil fuels with RES will not solve the problem, and lead us to understand why we need to accompany RES growth with other important and complex measures, the most important of which is certainly demand side management.

Let's start from the beginning... We don't need coal, oil, gas, or uranium, nor PV panels or wind turbines. What we really need is heat to keep our houses warm or for industrial production, electricity to run electrical equipment, and mechanical energy to move around and transport goods! If we look at the EU energy breakdown (Figure 9), these end uses amount to 37 Exajoules $^{1}$ (EJ), or 883 Mtoe: transportation covers $6 \%$ of total end uses, electricity has a $27 \%$ share, while heat is the dominant end use with the remaining 67\% share. However, the final energy (electricity, heat and fossil fuels for our cars and boilers) needed to produce this amount is about $58 \mathrm{EJ}$, with $21 \mathrm{EJ}$ lost mainly in the transportation sector, where only about $10 \%$ of the fuel heat content is converted by internal combustion engines into mechanical energy transferred to the wheels. Going further upstream, the primary energy supply exceeds 80 EJ, with another 22 EJ lost in power generation.

More than $50 \%$ of primary energy is therefore lost in the process which transforms it into final energy and from this to end uses. All of this waste is released as heat to the environment. If the heat demand could be at least partially covered by heat lost in energy conversion processes (and maybe internal combustion engines replaced by more efficient mechanical energy generators), a tremendous amount of primary energy could be saved (and $\mathrm{CO}_{2}$ emissions avoided).

\footnotetext{
${ }^{1}$ One exajoule (EJ) is equal to $1018 \mathrm{~J}$, or 23.86 million tons of oil equivalent (Mtoe).
} 
EJ

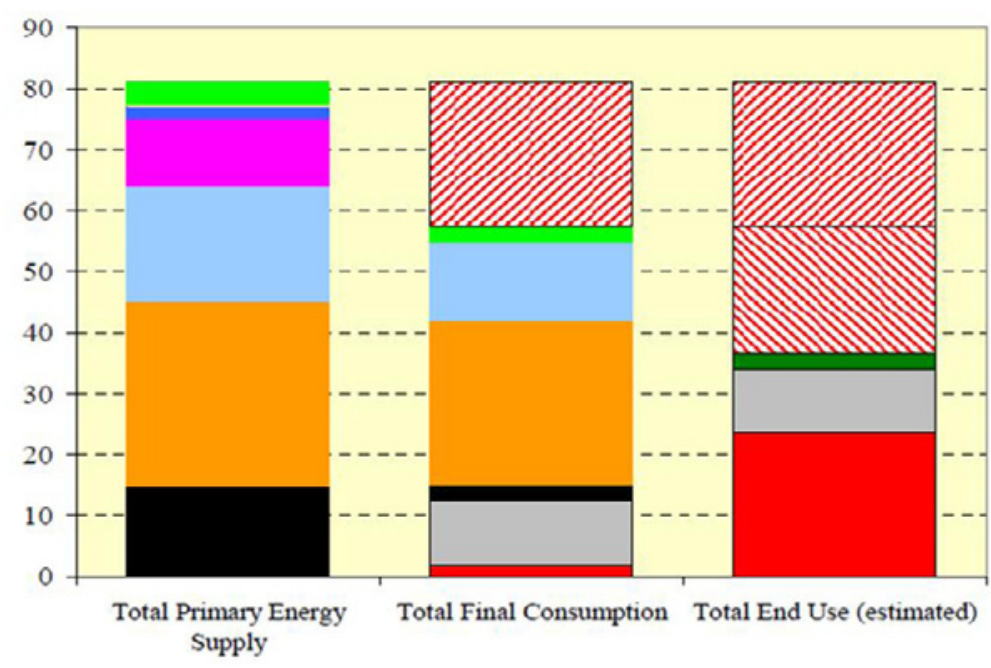

$\square$ Losses in the energy transformation sector

$\triangle$ Losses in end use

Combustible Renewables and Waste

Solar/Wind/Other

Geothermal

- Hydro

Nuclear

Natural Gas

- Petroleum Products

- Coal and Coal Products

- Transportation

$\square$ Electricity

$\square$ Heat

Figure 9- Total primary Energy supply, final consumption and end use in Europe [8].

In other words, less energy can be used for the same service (i.e., without changing the lifestyle of people) increasing energy efficiency: the energy demand of most users may be reduced, the efficiency of traditional energy conversion systems can be easily improved, and strong actions should be aimed at users to let them understand the value and not only the price of energy. In a systemic approach, incentives should also be considered by governments as effective policies to foster the start-up of new technologies until they become competitive.

In a word, one $\mathrm{kWh}$ saved is often better than one $\mathrm{kWh}$ produced by whatsoever source...

\section{The EU solution}

The EU answer to storms and monsters has been the so-called "20-20-20", duly taking into account the previous issues. By 2020 the EU should in fact achieve:

- a reduction in EU greenhouse gas emissions of at least $20 \%$ below 1990 levels

- $20 \%$ of EU energy consumption to come from renewable resources

- a $20 \%$ reduction in primary energy use compared with projected levels, to be achieved by improving energy efficiency.

Goals reached so far since the baseline year 2005 are quite promising. In 2011 RES have covered 13\% of final energy consumption ( $20.6 \%$ of electricity is renewable) in Europe, up by $4.5 \%$ in 6 years, and GHG emissions are $16 \%$ below 1990 levels.

What about Italy? Engagements assumed by Directive 2009/28/EC required RES to grow from $5.2 \%$ in 2005 to $17 \%$ in 2020. More specifically, for the three sectors (electricity, heat and transportation) the situation in 2005 and the goals for 2020 are described in Figure 10.

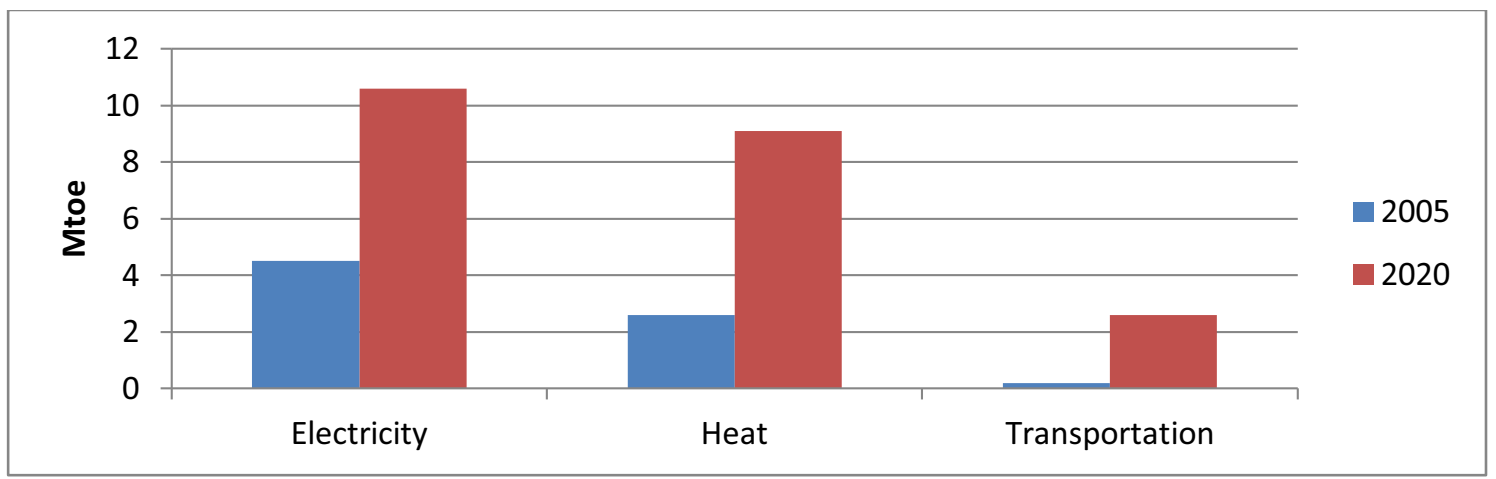

Figure 10 - Italy: “20-20-20” engagements: situation in 2005 and expectations for 2020. 


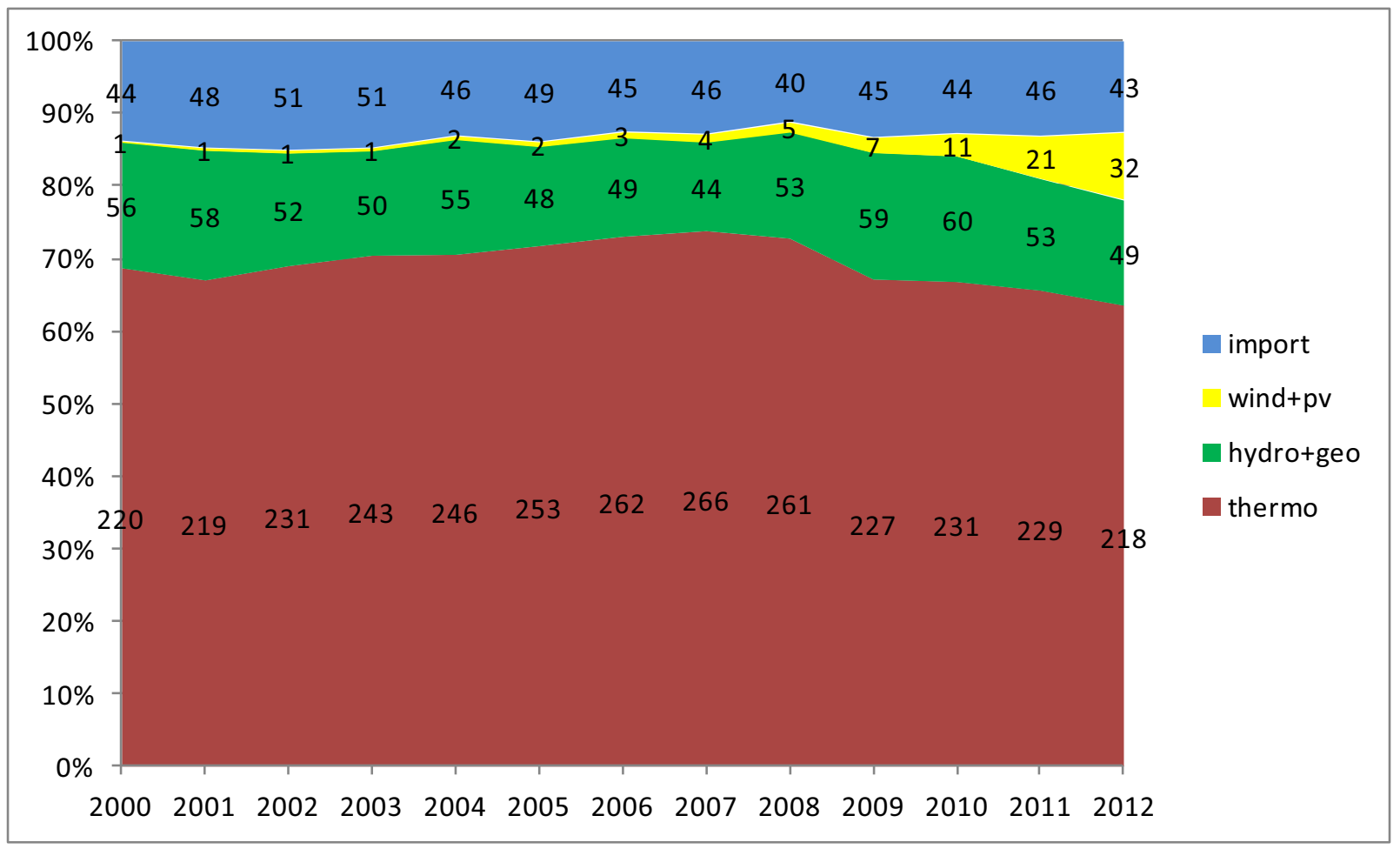

Figure 11 - Electricity consumption (\% and TWh) in Italy (2000-2012).

In 2005 (see fig. 11), with a total gross electricity consumption of $352 \mathrm{TWh}(1 \mathrm{Mtoe}=11.63 \mathrm{TWh}), 50 \mathrm{TWh}$ (or $14 \%$ of total consumption) came from renewable energy sources (96\% from hydro and geothermal), 253 TWh (72\%) were produced by thermal power plants burning fossil fuels, and the remaining $49 \mathrm{TWh}(13.9 \%)$ were imported.

In 2012, with more or less the same total gross consumption as in 2005 (349 TWh) renewable energy reached $82 \mathrm{TWh}$ (23.5\%), almost doubled respect to 2005, thanks to wind and PV which increased by a factor 16 in only 7 years. 43 TWh (12.3\%) were imported, and 218 TWh (down by 10 points to 62.5\%) were produced by power plants burning fossil fuels. Further progress is forecasted for 2013, meaning that the goals for 2020 are, on the electrical side, almost already reached. On the other hand, heat and transportation are still far from the target.

\section{Final considerations}

The extraordinary effort produced by the EU has to be acknowledged, and its results in terms of $\mathrm{CO}_{2}$ emissions is clearly visible (see figure 12). However, it's quite evident from the same figure that the situation with the rest of the world is completely different. While the $\mathrm{EU} \mathrm{CO}_{2}$ emissions in the period 2005-12 decreased from 7.5 to 7 billion tons, those of the rest of the World increased them from 21.5 to 27.5 billion tons $(+28 \%)$, making the whole balance grow from 29 to 34.5 billion tons $(+19 \%)$. 


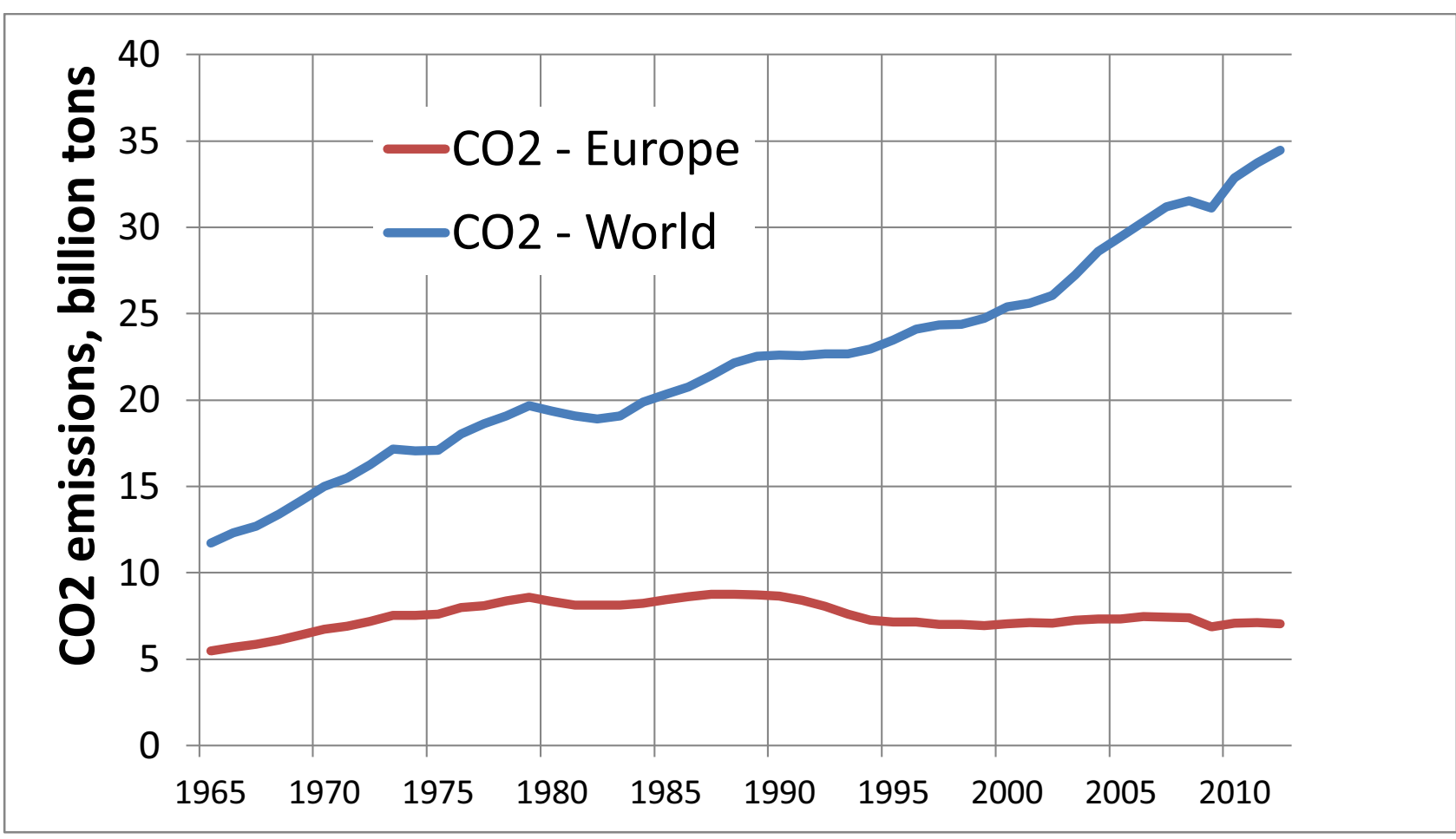

Figure $12-\mathrm{CO}_{2}$ emissions in Europe and in the World.

What else can we do if we want to stabilize $\mathrm{CO}_{2}$ emissions to $450 \mathrm{ppm}$, and limit the effects of global warming? In front of us we have a difficult choice between two alternative ways of thinking.

The first alternative would aim at fueling the increasing economic development of most world countries with "large size" and high impact carbon-free measures, such as:

- increase RES installations, if necessary covering square kilometres of fertile land for intensely exploiting RES

- $\quad$ increase the number of nuclear installations

- $\quad$ adopt Carbon Capture and Sequestration (CCS) techniques requiring, for a $1000 \mathrm{MW}$ coal plant, the injection of $6 \mathrm{Mt}$ ( 9 million cubic meters) of $\mathrm{CO}_{2}$ every year

- imitate volcanoes by geoengineering techniques requiring the injection of million tons of sulfur into the stratosphere in order to counteract the warming effect of $\mathrm{CO}_{2}$ concentration increase.

Some scientists strongly support these ideas, claiming that a negative opinion would reveal a "watermelon" (green skin but with a red heart) way of thinking.

The other alternative would be to understand that people's welfare may be separated by energy - whatever energy consumption.

In order to decarbonise our economy we should not only think of replacing fossil fuels with RES, but rather to adopt a new paradigm accommodating them in a completely different energy system where energy demand has been minimised, and heat, gas and power networks should become able to:

- host any clean energy source available

- handle two-directional energy flows (from centre to periphery and vice versa) so that the traditional difference between consumers and producers fades away and users become "prosumers"

- $\quad$ shave the demand power peaks using centralized and local storage facilities (water basins, clean and efficient batteries...),

- $\quad$ automatically switch among different energy networks (power to gas to heat.....) in order to satisfy the demand so that energy networks become intermodal like transportation networks.

In a few words, smart grid systems should be created, where demand is reduced, residual demand is always met with the cleanest available fuel and waste of energy is reduced to a minimum: not impossible, but a hard job in front of us!

\section{References}

1 World Resources Institute, http://www.wri.org/publication/navigating-numbers, 2005.

2 IUP, Institute für Umweltphysik, http://www.flickr.com/photos/41766005@N06/4042373874/

3 BP Statistical review of World Energy, http://www.bp.com/en/global/corporate/about-bp/statistical-review-ofworld-energy-2013.html, 2013. 
4 Steve Pacala, Princeton University Centre for Energy and Environmental Studies (PU-CEES), as reported by Robert Socolow at CLAIRE Convention, Politecnico di Torino, Pra Catinat, May 2013.

5 Robert Socolow, Princeton University Centre for Energy and Environmental Studies (PU-CEES), CLAIRE Convention, Politecnico di Torino, Pra Catinat, May 2013.

6 Trovò E., Moduli fotovoltaici ed emissioni di gas serra, Tesi di laurea, Politecnico di Torino, 2013.

7 Zubi, G., Future of Distributed Grid-Connected PV in South Europe. PhD Thesis, University of Zaragoza and Politecnico di Torino, 2010.

8 Ecoheatcool, WP1 - The European Heat Market, Final Report, http://www.euroheat.org/Files/Filer/ecoheatcool/documents/Ecoheatcool_WP1_Web.pdf, Bruxelles, 2006. 